\title{
The Response of Cockerel Semen Kinematic Parameters LIN, STR, WOB, ALH and BCF to Induced Oxidative Stress
}

\author{
Cyril Mpho Pilane ${ }^{1 *}$, Mohleko Helen Mapeka ${ }^{1,2}$ \\ ${ }^{1}$ Agricultural Research Council, Animal Production Campus, Germplasm Conservation \& Reproductive Biotechnologies, \\ Irene, South Africa \\ ${ }^{2}$ Department of Animal Production and Agricultural Economics, Faculty of Science and Agriculture, University of Limpopo, \\ Sovenga, South Africa \\ Email: *cyril@arc.agric.za
}

How to cite this paper: Pilane, C.M. and Mapeka, M.H. (2021) The Response of Cockerel Semen Kinematic Parameters LIN, STR, WOB, ALH and BCF to Induced Oxidative Stress. Open Journal of Animal Sciences, 11, 292-303.

https://doi.org/10.4236/ojas.2021.112022

Received: April 6, 2021

Accepted: April 27, 2021

Published: April 30, 2021

Copyright (c) 2021 by author(s) and Scientific Research Publishing Inc. This work is licensed under the Creative Commons Attribution International License (CC BY 4.0).

http://creativecommons.org/licenses/by/4.0/

\begin{abstract}
Computer-assisted sperm class analyser (CASA) analysis of avian semen following cryopreservation indicates that their semen motility and viability parameters become compromised, due in part to oxidative stress. To mimic these observations we have treated cockerel semen with an oxidative stress inducing agent, namely hydrogen peroxide $\left(\mathrm{H}_{2} \mathrm{O}_{2}\right)$ and monitored the motility, kinematic and viability parameters over time. Briefly, five healthy and fertile South African Venda cockerels were selected and their semen was collected using the abdominal massage technique. The semen was then treated with $\mathrm{H}_{2} \mathrm{O}_{2}$ at $0 \mu \mathrm{M}, 5 \mu \mathrm{M}, 50 \mu \mathrm{M}$ and $200 \mu \mathrm{M}$ concentrations for $0,3,16$ and $24 \mathrm{hrs}$. The semen motility, kinematic and viability parameters were then determined using the CASA system while the viability was determined using the SYBR-14/PI staining. The Pearson's correlation coefficient was determined to test the relationships between the levels of induced oxidative stress, period of exposure to oxidative stress inducing agent and the motility plus kinematic parameters. Our data revealed that in raw cockerel semen, there was high and positive correlations between total motility (TM), progressive motility (PM), rapid (RAP), curvilinear velocity (VCL), straight line velocity (VSL) and average path velocity (VAP) while the kinematic parameters LIN, STR, WOB, ALH and BCF had low or negative correlations with them. Furthermore, TM, PM, RAP, VCL and VSL remained highly and positively correlated with the induced oxidative stress and also, linearity (LIN), straightness (STR), wobble (WOB), amplitude of lateral head displacement (ALH) and beat cross frequency $(\mathrm{BCF})$ remained negatively correlated with the induced oxidative stress, after 3 hrs. After 24 hrs, TM, PM, RAP, VCL, VSL, VAP and ALH, be-
\end{abstract}


came negatively correlated with the induced oxidative stress while LIN, STR, WOB and BCF became positively correlated with the induced oxidative stress. Conversely, when the $\mathrm{H}_{2} \mathrm{O}_{2}$ concentration used was correlated with motility and kinematic parameters over time, TM, PM, RAP, VCL, VSL, VAP became negatively correlated with oxidative stress while LIN, STR, WOB, ALH and BCF show negative or low correlations with the induced oxidative stress. This data indicates that LIN, STR, WOB, BCF and to some extend ALH, reveal the least correlations with the induced oxidative stress under persistent oxidative stress conditions in cockerel semen. In conclusion, cockerel semen, like buck semen, does not easily succumb to oxidative stress since the raw semen correlations of CASA analysed parameters are comparable to these observed after $3 \mathrm{hrs}$ of $\mathrm{H}_{2} \mathrm{O}_{2}$ treatment. In addition, the oxidative stress levels tolerated by cockerel semen should not $5 \mu \mathrm{M} \mathrm{H}_{2} \mathrm{O}_{2}$ oxidative stress levels. Lastly, lack of correlation between LIN, STR, WOB, BCF and ALH and induced oxidative stress can be used in cockerel semen to show intolerable cryopreservation conditions.

\section{Keywords}

Cockerel, Oxidative Stress, Kinematic Parameters, Semen

\section{Introduction}

Cryopreservation of semen from various species has been shown to undergo oxidative stress [1] [2] [3] [4]. The cryopreservation induced oxidative stress in semen resulted in cellular damage including lipid peroxidation, DNA damage, membrane damage and reduced motility, velocity and viability parameters [2]. Cryopreserved avian semen undergoes the same fate due to their high membrane polyunsaturated fatty acid content, which is susceptible to oxidation [3] [4]. The generation of reactive oxygen species during semen cryopreservation has been implicated as the main culprits inflicting damage during oxidative stress [5] [6].

Our local Venda chickens have recently received much attention as part of the primary source of protein in poverty alleviation strategies [7]. They also possess desirable traits enjoyed by resource-poor small-scale farmers, which includes sexual maturity at 20 weeks and excellent fertility rates [8]. Previous cryopreservation of their semen has revealed that their fertility post-thaw have low semen motility, semen velocity and viability parameters, due in part to oxidative stress [8] [9]. In vitro, $\mathrm{H}_{2} \mathrm{O}_{2}$ induced oxidative stress mimics the cryopreservation induced sperm cell damage and compromised motility parameters as captured using CASA [10]. CASA technology allows for accurate and automated analysis of motility and kinematic patterns of each spermatozoa analysed showing their TM, PM, RAP VCL, VSL, VAP, LIN, STR, WOB, ALH and BCF values [11].

These men TM, PM and RAP have traditionally been used to determine fertil- 
ity [12]. The sperm kinematic parameters including average path velocity (VAP), velocity straight line (VSL), curvilinear velocity(VCL), amplitude lateral head displacement (ALH), beat cross frequency (BCF), straightness (STR), wobble (WOB), and linearity (LIN) provide valuable information that can be used to determine semen fertility depending on the threshold sensitivity settings of the CASA system [11] [13]. In boars and bulls, the spermatozoa kinematic parameters such as BCF, ALH, and LIN were positively correlated with fertility [14]. Also, both LIN and BCF correlated with ALH and showed linear progression as shown in sperm penetration assays [14] [15]. When stallion sperm samples were analysed by CASA, an increase in ALH, flagella bend amplitude and beat symmetry showed hyperactivated motility [15] [16]. In addition, an abrupt increase of STR at the onset of sperm hyperactivation was accompanied by the gradual increase in LIN in hamster sperm [16]. All these observations indicate that the semen kinematic parameters can be used to predict fertility.

We have previously shown that in boars, induced oxidative stress decreased LIN and STR, which were restored to raw semen values by an antioxidant, indicating that the use of antioxidants improved semen fertility [17]. In South African indigenous unimproved bucks, induced oxidative stress increased LIN, STR and WOB with or without antioxidants, indicating that buck semen under oxidative stress can remain fertile despite the presence or absence of antioxidants [10] [17]. In cockerels, semen motility parameters such as TM, PM, and RAP have been extensively used to investigate fertility during cryopreservation or oxidative stress [12] [18]. The implications of the changes in the kinematic parameters following cryopreservation have received little attention. To address this, we have mimicked the cryopreservation induced oxidative stress by using $\mathrm{H}_{2} \mathrm{O}_{2}$ to investigate its effects on cockerel semen kinematic parameters. In this study, we show that the kinematic parameters BCF, WOB, LIN, STR show positive correlations with induced oxidative stress over extended periods in cockerel semen.

\section{Materials and Methods}

The study was conducted at the Poultry research unit and Germplasm Conservation \& Reproductive Biotechnologies unit of the Agricultural Research Council (ARC), Irene, South Africa. The ARC-Irene campus is located at $25^{\circ} 55^{\prime}$ South; $28^{\circ} 12^{\prime}$ East. The institute is located in the Highveld region of South Africa and situated at an altitude of 1525 meters above sea level. Five Venda cocks, in good health condition, were identified and used for semen collection. This study was carried out in strict accordance with the recommendations in the Guide for the Care and Use of Animals under the guidelines of the Agricultural Research Council, Animal Production Institute Animal Ethics Committee (APIEC08/06). Water was given ad libitum throughout the duration of the study.

\subsection{Cockerel Semen Collection and Processing}

Semen was collected from five Venda cockerels using the gloved-hand tech- 
nique. After collection, the semen samples were placed into the thermo-flask at $37^{\circ} \mathrm{C}$ and transported to the laboratory. In the laboratory semen evaluations were performed within $1 \mathrm{~h}$. Semen motility rates and velocity rates were assessed using the CASA system (Sperm Class Analyzer ${ }^{\circledast}$ [SCA] 5.0, Microptic, Barcelona, Spain), semen viability was evaluated using the SYBR/PI live/dead kit (Invitrogen, Molecular probes, USA).

\subsection{Treatments}

For semen treatment, $\mathrm{H}_{2} \mathrm{O}_{2}$ stock solution was prepared in pre-warmed BO-Wash and kept at $4{ }^{\circ} \mathrm{C}$ until use. During the experiment, semen at equal concentration and volume was treated with pre-warmed $\mathrm{H}_{2} \mathrm{O}_{2}$ stock to make $0,5 \mu \mathrm{M}, 50 \mu \mathrm{M}$ and $200 \mu \mathrm{M}$ concentrations. The treated cells were then incubated at $37^{\circ} \mathrm{C}$ for zero, three, sixteen and twenty four hours in a humidified $5 \% \mathrm{CO}_{2}$ and $95 \%$ atmospheric air incubator (Sanyo, Japan). After three, sixteen and twenty four hours the cells were evaluated for total motility, progressive motility, rapid motility, semen velocities parameters, semen kinematic parameters and semen viability.

\subsection{Sperm Motility Rate}

About $10 \mu \mathrm{l}$ of raw or experimental semen was placed into $50 \mu \mathrm{l}$ of BO-Wash medium in $15 \mathrm{ml}$ tube (Falcon ${ }^{\otimes} 352099$, USA). The tube was then kept in $\mathrm{CO}_{2}$ incubator (Sanyo, Japan) adjusted to $37^{\circ} \mathrm{C}$. Five micro litres of semen was placed on the warm glass slide $(\sim 76 \times 26 \times 1 \mathrm{~mm}$, Germany) and placed with a warmed cover slip $(22 \times 22 \mathrm{~mm}$, Germany) over the microscope-warm plate (Omron) adjusted at $37^{\circ} \mathrm{C}$. The sperm motility rates (Table 1 ) were evaluated using CASA system (Sperm Class Analyzer ${ }^{\circledast}$ [SCA] 5.0, Microptic, Barcelona, Spain) at the $10 \mathrm{X}$ magnification (Nikon, China).

\subsection{Viability Assay}

For cell viability, SYBR-14 and PI Live/Dead kit was used and the cells were treated according to the manufacturer's recommendation (Invitrogen, Molecular

Table 1. The cockerel raw semen total motility (TM), Progressive motility (PM), Rapid motility (RAP) and Viability of five cockerel and and the averages expressed as mean \pm S.D.

\begin{tabular}{ccccccc}
\hline Percentage (\%) & C1 & C2 & C3 & C4 & C5 & Average \\
\hline Total Motility & $75.6 \pm 7.4$ & $95.6 \pm 5.4$ & $92.1 \pm 6.2$ & $69.6 \pm 7.3$ & $84.7 \pm 3.6$ & $83.52 \pm 9.7$ \\
Rapid motility & $14.6 \pm 2.5$ & $29.4 \pm 3.2$ & $21.6 \pm 3.2$ & $8.2 \pm 2.2$ & $18.9 \pm 3.1$ & $18.54 \pm 7.1$ \\
Progressive motility & $13.3 \pm 2.1$ & $22.5 \pm 4.8$ & $17.7 \pm 5.2$ & $10.1 \pm 1.3$ & $14.8 \pm 4.8$ & $15.68 \pm 4.2$ \\
Viability & $97.2 \pm 6.3$ & $98.0 \pm 1.3$ & $97.4 \pm 1.6$ & $95.4 \pm 4.7$ & $96.1 \pm 2.9$ & $96.82 \pm 0.9$ \\
\hline
\end{tabular}


probes, USA). Briefly, $50 \mu \mathrm{l}$ of semen was diluted with pre-warmed BO-Wash to $1 \mathrm{ml}$ and $5 \mu \mathrm{l}$ of 50 times diluted SYBR-14 was added to the cells followed by incubation at $37^{\circ} \mathrm{C}$ for 10 minutes. After 10 minutes, $5 \mu \mathrm{l}$ of propidium iodide was added to the cells followed by incubation for another 10 minutes. After $10 \mathrm{mi}$ nutes $5 \mu \mathrm{l}$ of cells was immediately placed on pre-warmed glass slide and observed under a fluorescent microscope at 60X (Olympus, model BX51). For this analysis, viable cells appear green in colour while non-viable cells appear red in colour. The percent cell viability was determined by counting the number of green cells out of a hundred cells per field repeated three times. The data was represented in a table as percent viability versus $\mathrm{H}_{2} \mathrm{O}_{2}$ concentrations.

\subsection{Data Analysis}

The viability data was expressed as a percentage of total cells observed in a field, out of 300 sperm cells observed. Pearson's correlation coefficients were calculated to test the relationship between the motility and kinematic parameters, namely, TM, PM, RAP, VCL, VSL, VAP, LIN, STR, WOB and viability against the treatments. Data were examined using the Kolmogorov-Smirnov test to determine their distribution, a multivariate analysis of variance was performed (ANOVA) and when significant differences were found, and the non-parametric Mann-Whitney U-test was used to compare pairs of values directly if data did not adjust to a normal distribution. All analyses were performed using SPSS version 17.0 for Windows (SPSS Inc., Chicago, IL). Significance was set at $\mathrm{p}<0.05$.

\section{Results}

Raw cockerel semen has high motility and viability parameters. All five cockerels showed average semen total motility of $83.52 \pm 9.7$, average rapid motility of $18.54 \pm 7.1$, average progressive motility of $15.68 \pm 4.2$ and average percent viability of $96.82 \pm 0.3$ (Table 1). In raw semen, the relationship between the motility and the kinematic parameters revealed that there is a high positive correlation between TM, PM, RAP, HYP, VSL, VCL and VAP. However, LIN, STR, WOB, and BCL had a poor or negative correlation with TM, PM, RAP, HYP, VCL and VAP but high positive correlations among themselves, except for ALH (Table 2).

Furthermore, CASA analysis shows that visually, there was a high number of rapidly moving sperm cells (red) accompanied by progressive (green) and nonprogressive motility (blue) in just 3 hrs (Figure $1(A)-(D)$ ). This observation was further illustrated by the high positive correlations between motility parameters TM, PM, RAP, VCL and induced oxidative stress. For the kinematic parameters, HYP, VCL and VSL showed positive correlations with the induced oxidative stress. Other kinematic parameters, namely, VAP, LIN, STR, WOB, BCF and ALH reveal low or negative correlations of $-0.667,-0.673-0.525,0.319,-0.274$ and 0.03 , respectively. Interestingly, there were no correlations between viability and the induced oxidative stress at $3 \mathrm{hrs}$. 
Table 2. The Venda cockerel raw semen motility and kinematic parameters showing Pearson's correlation among these parameters.

\begin{tabular}{|c|c|c|c|c|c|c|c|c|c|c|c|c|}
\hline & $\mathrm{TM}$ & $\mathrm{PM}$ & RAP & HYP & VCL & VSL & VAP & LIN & STR & WOB & $\mathrm{BCF}$ & $\mathrm{ALH}$ \\
\hline $\mathrm{TM}$ & 1.0 & & & & & & & & & & & \\
\hline $\mathrm{PM}$ & 0.836 & 1.0 & & & & & & & & & & \\
\hline RAP & 0.864 & 0.832 & 1.0 & & & & & & & & & \\
\hline HYP & 0.746 & 0.87 & 0.918 & 1.0 & & & & & & & & \\
\hline VCL & 0.8853 & 0.777 & 0.990 & 0.8624 & 1.0 & & & & & & & \\
\hline VSL & 0.775 & 0.968 & 0.800 & 0.8738 & 0.732 & 1.0 & & & & & & \\
\hline VAP & 0.9036 & 0.934 & 0.957 & 0.9253 & 0.928 & 0.9308 & 1.0 & & & & & \\
\hline LIN & 0.0932 & 0.479 & -0.012 & 0.2488 & -0.12 & 0.5869 & 0.2558 & 1.0 & & & & \\
\hline STR & -0.079 & 0.363 & -0.138 & 0.1542 & -0.25 & 0.4692 & 0.1154 & 0.9825 & 1.0 & & & \\
\hline WOB & 0.2465 & 0.565 & 0.101 & 0.3307 & 0.006 & 0.6727 & 0.3754 & 0.9823 & 0.931 & 1.0 & & \\
\hline $\mathrm{BCF}$ & 0.4907 & 0.764 & 0.287 & 0.4195 & 0.213 & 0.7622 & 0.5279 & 0.8503 & 0.777 & 0.88 & 1.0 & \\
\hline ALH & 0.1383 & -0.04 & 0.483 & 0.2814 & 0.531 & -0.086 & 0.2223 & -0.768 & -0.77 & -0.74 & -0.65 & 1.0 \\
\hline
\end{tabular}
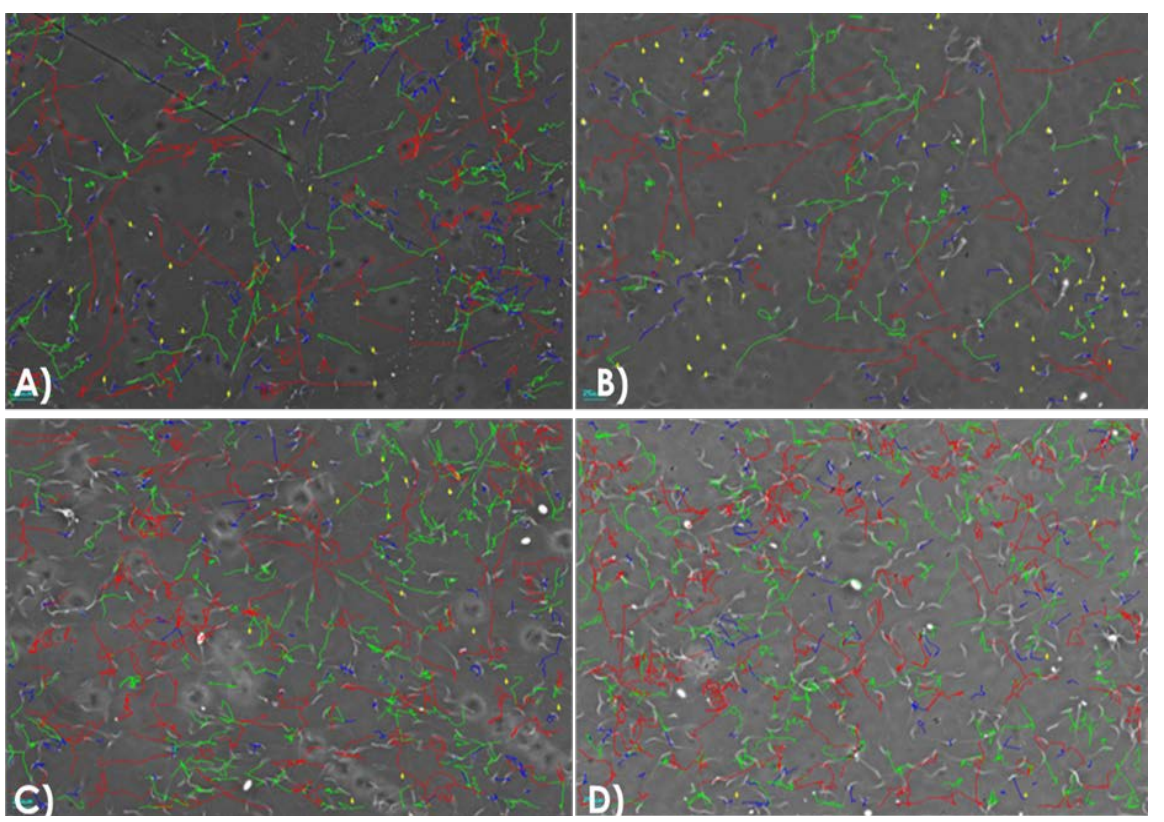

Figure 1. The CASA analysed cockerel semen treated with(A) $0 \mu \mathrm{M} \mathrm{H}_{2} \mathrm{O}_{2}$, (B) $5 \mu \mathrm{M}$ $\mathrm{H}_{2} \mathrm{O}_{2}$, (C) $50 \mu \mathrm{M} \mathrm{H}_{2} \mathrm{O}_{2}$ and (D) $200 \mu \mathrm{M} \mathrm{H}_{2} \mathrm{O}_{2}$ after 3 hrs showing rapidly (RAP) moving cells (red), progressively moving (PM) cells (green), non-progressively moving (blue) cells and static (yellow) cells at 10× magnification. 
Beyond $3 \mathrm{hrs}$, the pattern of correlation between the induced oxidative stress and the motility plus kinematic parameters changed. TM, PM, and RAP revealed a progressively negative correlation with the induced oxidative stress. On the other hand, the kinematic parameters like VCL, VSL, VAP, ALH also showed high negative correlations with the induced oxidative stress. Ironically, LIN, STR, WOB and BCF began to show progressively positive correlations with the induced oxidative stress beyond $3 \mathrm{hrs}$. This observation was further confirmed by a high percentage of progressive (green) and non-progressively (blue) motile sperm cells, but less or no rapidly (red) moving cells (Figure 2(A)-(D)). The viability analysis confirmed that they had a high and negative correlation with the induced oxidative stress beyond $3 \mathrm{hrs}$ (Table 3, Figure 3(A)-(D)).

Conversely, an investigation of the motility and kinematic parameters correlations with the induced oxidative stress over time revealed that TM, PM, and RAP remain negatively correlated all oxidative stress levels including the zero levels of the induced oxidative stress. In addition, at zero levels of induced oxidative stress, all parameters show high negative correlations including at $5 \mu \mathrm{M}$ $\mathrm{H}_{2} \mathrm{O}_{2}$ levels of induced oxidative stress. However, beyond $5 \mu \mathrm{M} \mathrm{H} \mathrm{H}_{2} \mathrm{O}_{2}$ levels of induced oxidative stress, LIN, STR, WOB and BCF began to show marginal or moderate correlations with the induced oxidative stress over time. At $200 \mu \mathrm{M}$ $\mathrm{H}_{2} \mathrm{O}_{2}$ levels of induced oxidative stress, WOB, and ALH showed correlations of -0.58 and 0.589 , respectively (Table 4 ). This data appear to imply that at persistent induced oxidative stress levels, both LIN and STR, are not influenced by the oxidative stress condition while WOB and ALH showed variable but moderate responses to induced oxidative stress.
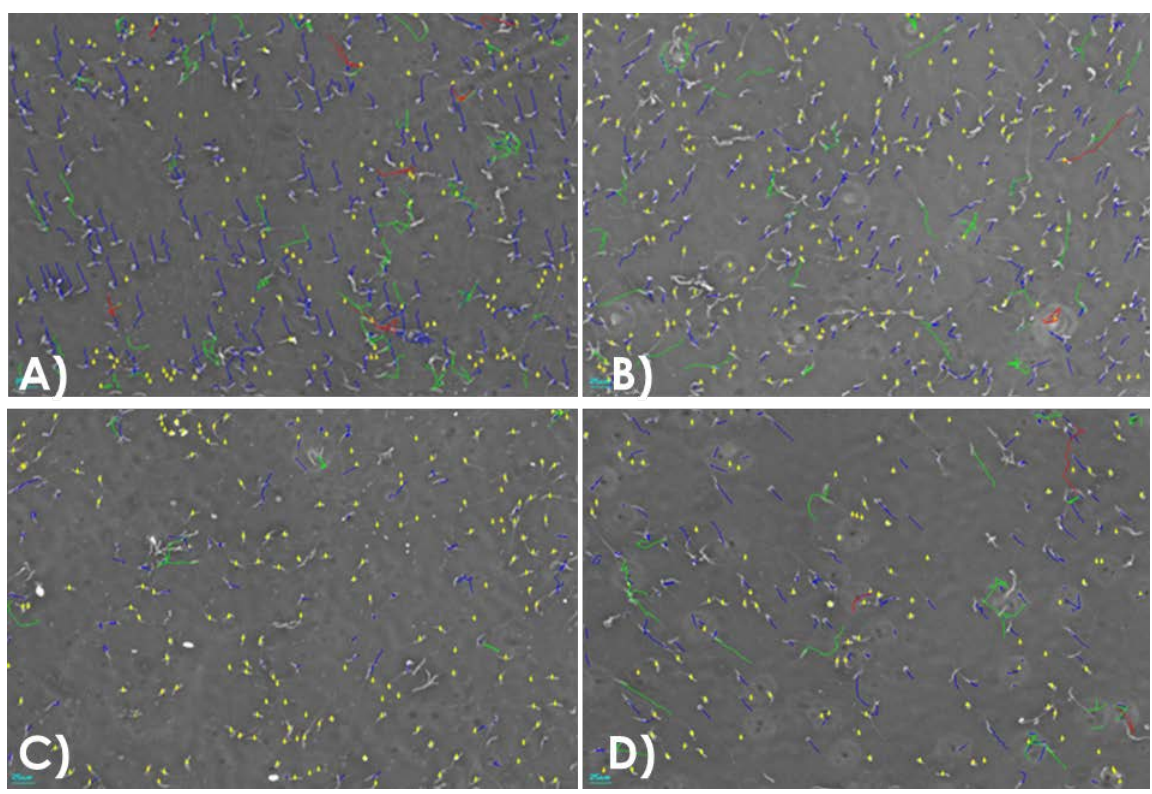

Figure 2. The CASA analysed cockerel semen treated with (A) $0 \mu \mathrm{M} \mathrm{H}_{2} \mathrm{O}_{2}$, (B) $5 \mu \mathrm{M}$ $\mathrm{H}_{2} \mathrm{O}_{2}$, (C) $50 \mu \mathrm{M} \mathrm{H}_{2} \mathrm{O}_{2}$ and (D) $200 \mu \mathrm{M} \mathrm{H}_{2} \mathrm{O}_{2}$ after 24 hrs showing rapidly (RAP) moving cells (red), progressively moving (PM) cells (green), non-progressively moving (blue) cells and static (yellow) cells at $10 \times$ magnification. 

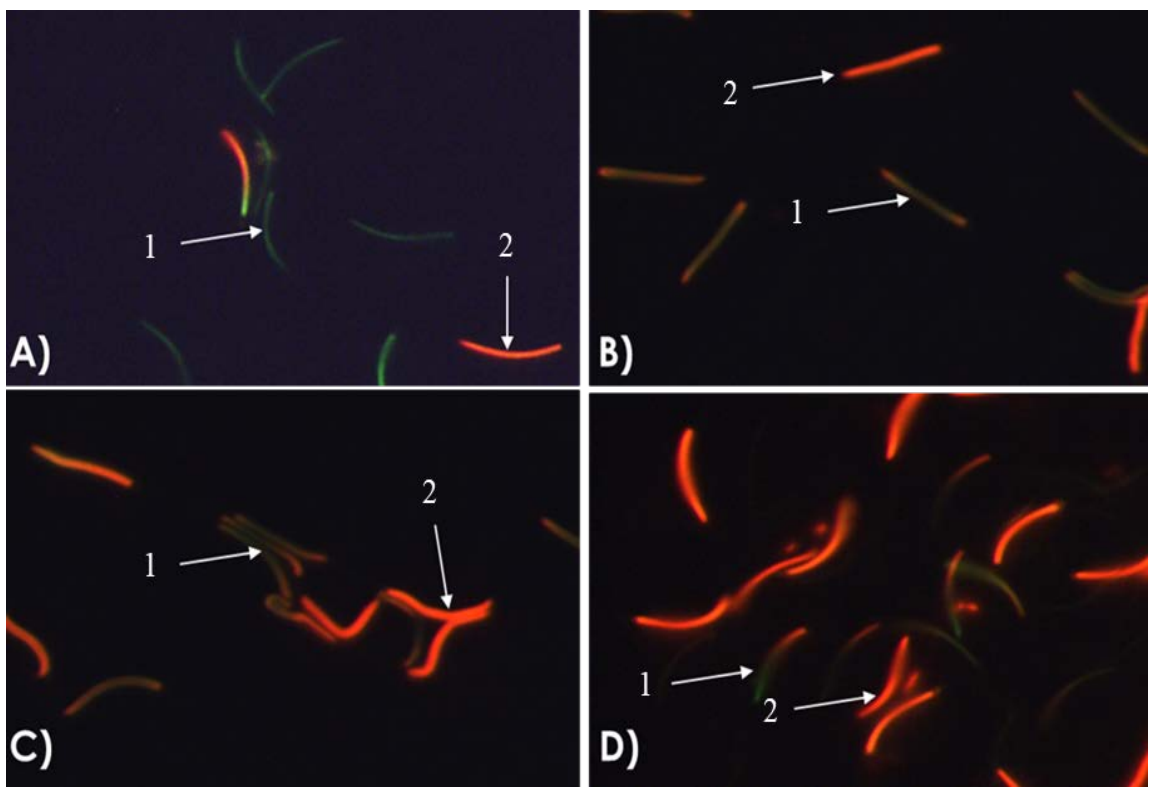

Figure 3. The Venda cockerel semen viability determined by staining with SYBR-14/PI for semen treated with (A) $0 \mu \mathrm{M} \mathrm{H}_{2} \mathrm{O}_{2}$, (B) $5 \mu \mathrm{M} \mathrm{H}_{2} \mathrm{O}_{2}$, (C) $50 \mu \mathrm{M} \mathrm{H}_{2} \mathrm{O}_{2}$ and (D) $200 \mu \mathrm{M}$ $\mathrm{H}_{2} \mathrm{O}_{2}$ after 16 hrs of treatment, where the green cells [1] indicates live or moribund live cells and red cells [2] indicating dead or non-viable cells at $100 \times$ of magnification.

Table 3. The Venda cockerel semen treated with $\mathrm{H}_{2} \mathrm{O}_{2}$ showing Pearson's correlation coefficient of motility and kinematic parameters with time.

\begin{tabular}{|c|c|c|c|}
\hline & $3 \mathrm{hrs}$ & $16 \mathrm{hrs}$ & $24 \mathrm{hrs}$ \\
\hline $\mathrm{TM}$ & 0.921 & -0.308 & -0.994 \\
\hline $\mathrm{PM}$ & 0.529 & -0.36 & -0.901 \\
\hline RAP & 0.675 & -0.01 & -0.985 \\
\hline HYP & 0.482 & 0.804 & -0.407 \\
\hline VCL & 0.693 & -0.314 & -0.916 \\
\hline VSL & 0.560 & -0.33 & -0.69 \\
\hline VAP & -0.667 & -0.267 & -0.846 \\
\hline LIN & -0.673 & 0.521 & 0.854 \\
\hline STR & -0.525 & -0.099 & 0.989 \\
\hline WOB & 0.319 & 0.135 & 0.52 \\
\hline $\mathrm{BCF}$ & -0.274 & 0.035 & 0.882 \\
\hline ALH & 0.03 & -0.524 & -0.683 \\
\hline Viability & 0.064 & -0.989 & -0.828 \\
\hline
\end{tabular}


Table 4. The Venda cockerel semen treated over time showing the Pearson's correlation coefficient of motility and kinematic parameters with $0 \mu \mathrm{M}, 5 \mu \mathrm{M}, 50 \mu \mathrm{M}$ and $200 \mu \mathrm{M}$ $\mathrm{H}_{2} \mathrm{O}_{2}$.

\begin{tabular}{|c|c|c|c|c|}
\hline & $0 \mu \mathrm{M} \mathrm{H}_{2} \mathrm{O}_{2}$ & $5 \mu \mathrm{M} \mathrm{H}_{2} \mathrm{O}_{2}$ & $50 \mu \mathrm{M} \mathrm{H}_{2} \mathrm{O}_{2}$ & $200 \mu \mathrm{M} \mathrm{H}_{2} \mathrm{O}_{2}$ \\
\hline $\mathrm{TM}$ & -0.982 & -0.87 & -0.99 & -0.91 \\
\hline $\mathrm{PM}$ & -0.856 & -0.94 & -0.91 & -0.855 \\
\hline RAP & -0.81 & -0.887 & -0.86 & -0.774 \\
\hline HYP & -0.781 & -0.894 & -0.867 & -0.864 \\
\hline VCL & -0.892 & -0.997 & -0.91 & -0.784 \\
\hline VSL & -0.928 & -0.99 & -0.887 & -0.861 \\
\hline VAP & -0.948 & -0.997 & -0.896 & -0.84 \\
\hline LIN & -0.85 & -0.895 & 0.187 & -0.138 \\
\hline STR & -0.734 & -0.901 & 0.0089 & 0.175 \\
\hline WOB & -0.911 & -0.87 & -0.0019 & -0.58 \\
\hline $\mathrm{BCF}$ & -0.86 & -0.83 & -0.500 & -0.81 \\
\hline ALH & -0.767 & -0.691 & -0.882 & 0.589 \\
\hline
\end{tabular}

\section{Discussions}

The conventional semen quality traits including motility, viability, and sperm kinematic parameters are important traits, which provide voluble information for comprehensive evaluation of cockerel fertility. Selection of roosters based on semen quality traits especially motility and sperm kinematics parameters for artificial insemination may improve the fertility rate [19]. In Venda cockerels, the raw semen motility, velocity and other kinematic parameters show opposing levels where TM, PM, RAP, VCL, VSL, and VAP are high while STR, WOB, ALH, LIN, and BCF were generally low. This observation is in agreement with previous data on the cryopreservation of semen from these cockerels using the slow freezing or the vitrification methods, which revealed that LIN, STR, WOB, ALH and $\mathrm{BCF}$ showed minimal changes irrespective of the cryopreservation method used [8].

Under oxidative stress conditions, over time ( $24 \mathrm{hrs),} \mathrm{the} \mathrm{relationship} \mathrm{of} \mathrm{these}$ parameters with levels of oxidative stress is reversed where TM, PM, RAP, VCL, VSL, and VAP show negative correlations with induced oxidative stress while STR, LIN, WOB and BCF begin to have high and positive correlations with the induced oxidative stress. It is evident that exposure of cockerel semen to oxidative stress for a short period ( $3 \mathrm{hrs}$ ) results in hyper-activation of the sperm cells beyond which ( $24 \mathrm{hrs}$ ) the hyper-activation is lost. Accompanying the lost hyper-activation is the loss of TM, PM, RAP, VCL, VSL, VAP and ALH, as the via- 
bility is lost. We have previously shown that in boars, semen RAP and VAP showed a high positive correlation with increased oxidative stress at 0.798 and 0.623 , respectively, after 3 hrs. Conversely, TM, VCL, VSL, STR and WOB had negative correlations with oxidative stress at $-0.368,-0.753,-0.352,-0.839$ and -0.919 , respectively. In unimproved indigenous buck semen, only VSL, LIN, STR and WOB revealed moderately high positive correlations of $0.562,0.0 .489$, 0.424 and 0.235 , respectively, with only TM and RAP low or negative correlation of 0.182 and -0.557 , respectively, with induced oxidative stress after $3 \mathrm{hrs}$. These data revealed that unimproved indigenous buck semen does not easily succumb to oxidative stress while boar semen was highly susceptible to oxidative stress. Moreover, in this paper, cockerel semen does not seem to easily succumb to oxidative stress after $3 \mathrm{hrs}$ as compared to other species [10] [17].

Interestingly, an investigation of the response of the Venda cockerel sperm cells to different levels of $\mathrm{H}_{2} \mathrm{O}_{2}$ induced oxidative stress suggests that these cells can tolerate the induced oxidative stress of $5 \mu \mathrm{M}$ levels of induced oxidative stress over a period of $24 \mathrm{hrs}$. Only the non-treated and $5 \mu \mathrm{M}$ treated semen indicates a high although negative correlations with the period of exposure to various $\mathrm{H}_{2} \mathrm{O}_{2}$-induced oxidative stress levels for all the motility and kinematic parameters investigated. Beyond $5 \mu \mathrm{M}$ level of induced oxidative stress, all the motility and kinematic parameters show a high negative correlation with $50 \mu \mathrm{M}$ and $200 \mu \mathrm{M}$ levels of induced oxidative stress except for LIN, STR, WOB, BCF and to some extend ALH.

\section{Conclusion}

This data indicates that the presence of an oxidative stress-inducing agent above $50 \mu \mathrm{M}$ is too lethal such that LIN, STR and WOB were compromised. Surprisingly, ALH show an intermediate but positive correlation with induced oxidative stress, indicating that ALH is not affected at high oxidative stress such as at $200 \mu \mathrm{M} \mathrm{H}_{2} \mathrm{O}_{2}$. These observations indicate that during cryopreservation, the levels of Venda cockerel semen exposure to oxidative stress cannot exceed the 5 $\mu \mathrm{M} \mathrm{H}_{2} \mathrm{O}_{2}$ induced levels. Also, this data shows that when Venda cockerel semen is exposed to high and persistent oxidative stress, the kinematic parameters LIN, STR, WOB, BCF and ALH show the least correlation with oxidative stress and can thus be used as alternative indicators for compromised semen fertility.

\section{Acknowledgements}

The authors wish to acknowledge the Agricultural Research Council (ARC) and the Department of Forestry and Fisheries (DAFF) for providing necessary facilities and financial support.

\section{Conflicts of Interest}

The authors declare no conflicts of interest regarding the publication of this paper. 


\section{References}

[1] Evangelista-Vargas, S. and Santiani, A. (2017) Detection of Intracellular Reactive Oxygen Species (Superoxide Anion and Hydrogen Peroxide) and Lipid Peroxidation During Cryopreservation of Alpaca Spermatozoa. Reproduction in Domestic Animals, 52, 819-824. https://doi.org/10.1111/rda.12984

[2] Len, J.S., Koh, W.S.D. and Tan, S.-X. (2019) The Roles of Reactive Oxygen Species and Antioxidants in Cryopreservation. Bioscience Reports, 39, Article ID: BSR20191601. https://doi.org/10.1042/BSR20191601

[3] Surai, P.F. (1998) Lipid Peroxidation in Avian Semen: Protective Effect of Seminal Plasma. British Poultry Science, 39, 57-58. https://doi.org/10.1080/00071669888403

[4] Bucak, M.N., Sarı̈̈zkan, S., Tuncer, P.B., Sakin, F., Atessahin, A., Kulaksız, R. and Cevik, M. (2010) The Effect of Antioxidants on Post-Thawed Angora Goat (Capra hircus ancryrensis) sperm parameters, Lipid Peroxidation and Antioxidant Activities. Small Ruminant Research, 89, 24-30. https://doi.org/10.1016/j.smallrumres.2009.11.015

[5] Kadirvel, G., Kumar, S. and Kumaresan, A. (2009) Lipid Peroxidation, Mitochondrial Membrane Potential and DNA Integrity of Spermatozoa in Relation to Intracellular Reactive Oxygen Species in Liquid and Frozen-Thawed Buffalo Semen. Animal Reproduction Science, 114, 125-134.

https://doi.org/10.1016/j.anireprosci.2008.10.002

[6] Bollwein, H. and Bittner, L. (2018) Impacts of Oxidative Stress on Bovine Sperm Function and Subsequent in Vitro Embryo Development. Animal Reproduction, 15, 703-710. https://doi.org/10.21451/1984-3143-AR2018-0041

[7] Dube, M.H., Francis, J. and Maliwichi, L.L. (2016) Poultry-Based Poverty Alleviation Projects in Ehlanzeni District Municipality: Do They Contribute to the South African Government's Developmental State' Ambition? South African Journal of Agricultural Extension, 44, 147-157. https://doi.org/10.17159/2413-3221/2016/v44n2a408

[8] Mphaphathi, M.L., Seshoka, M.M., Luseba, D., Sutherland, B. and Nedambale, T.L. (2016) The Characterisation and Cryopreservation of Venda Chicken Semen. Asian Pacific Journal of Reproduction, 5, 132-139. https://doi.org/10.1016/j.apjr.2016.01.009

[9] Yániz, J.L., Palacín, I., Caycho, K.S., Soler, C., Silvestre, M.A. and Santolaria, P. (2018) Determining the Relationship between Bull Sperm Kinematic Subpopulations and Fluorescence Groups Using an Integrated Sperm Quality Analysis Technique. Reproduction, Fertility, and Development, 30, 919-923. https://doi.org/10.1071/RD17441

[10] Pilane, C.M., Bopape, M.A., Ntombizodwa, B. and Mapeka, M.H. (2019) Buck Semen Does Not Easily Succumb to Oxidative Stress. Open Journal of Animal Sciences, 9, 65-75. https://doi.org/10.4236/ojas.2019.91006

[11] Amann, R. and Waberski, D. (2014) Computer-Assisted Sperm Analysis (CASA): Capabilities and Potential Developments. Theriogenology, 81, 5-17. https://doi.org/10.1016/j.theriogenology.2013.09.004

[12] Seshoka, M.M., Mphaphathi, M.L. and Nedambale, T.L. (2016) Comparison of Four Different Permitting and Combination of Two Best Cryoprotectants on Freezing Nguni Sperm Evaluated with the Aid of Computer Aided Sperm Analysis. Cryobiology, 72, 232-238. https://doi.org/10.1016/j.cryobiol.2016.04.001

[13] Yang, Y., Zhang, Y., Ding, J., Ai, S., Guo, R., Bai X. and Yang, W. (2019) Optimal Analysis Conditions for Sperm Motility Parameters with a CASA System in a Pas- 
serine Bird, Passer montanus. Avian Research, 10, Article No. 35. https://doi.org/10.1186/s40657-019-0174-5

[14] Larsen, L., Scheike, T., Jensen, T.K., Bonde, J.P., Ernst, E., Hjollund, N.H., Zhou, Y., Skakkebaek, N.E. and Giwercman, A. (2000) Computer-Assisted Semen Analysis Parameters as Predictors for Fertility of Men from the General Population. Human Reproduction, 15, 1562-1567. https://doi.org/10.1093/humrep/15.7.1562

[15] McPartlin, L.A., Suarez, S.S., Czaya, C.A., Hinrichs, K. and Bedford-Guaus, S.J. (2009) Hyperactivation of Stallion Sperm Is Required for Successful In Vitro Fertilization of Equine Oocytes. Biology of Reproduction, 81, 199-206.

https://doi.org/10.1095/biolreprod.108.074880

[16] Kinukawa, M., Nagata, M. and Aoki, F. (2003) Changes in Flagellar Bending During the Course of Hyperactivation in Hamster Spermatozoa. Reproduction, 125, 43-51. https://doi.org/10.1530/rep.0.1250043

[17] Pilane, C.M., Bopape, M.A., Mapeka, M.H. and Netshirovha, T.R. (2016) Assessment of the Susceptibility of Boar Semen to Oxidative Stress. Open Journal of Animal Sciences, 6, 123-130. https://doi.org/10.4236/ojas.2016.62015

[18] Valverde, A., Barquero, V. and Soler, C. (2020) The Application of ComputerAssisted Semen Analysis (CASA) Technology to Optimise Semen Evaluation, A review. Journal of Animal and Feed Sciences, 29, 189-198. https://doi.org/10.22358/jafs/127691/2020

[19] Tesfay, H.H., Sun,Y., Li, Y., Shi, L., Fan, J., Wang, P., Zong, Y., Ni, A., Ma, H., Mani, A.I. and Chen J. (2020) Comparative Studies of Semen Quality Traits and Sperm Kinematic Parameters in Relation to Fertility Rate between 2 Genetic Groups of Breed lines. Poultry Science, 99, 6139-6146.

https://doi.org/10.1016/j.psj.2020.06.088 